\title{
Involvement of the Areae Compositae of the Heart in Endemic Pemphigus Foliaceus
}

\author{
Ana Maria Abreu-Velez ${ }^{1}$, Yulieth A. Upegui-Zapata², Carlos A. Valencia-Yepes ${ }^{3}$, \\ Eduardo Upegui-Quiceno ${ }^{4}$, Alejandra M. Jiménez-Echavarría ${ }^{4}$, César D. Niño-Pulido ${ }^{5}$, \\ Bruce R. Smoller ${ }^{6}$, Michael S. Howard ${ }^{1}$
}

\author{
1 Georgia Dermatopathology Associates, Atlanta, GA, USA \\ 2 PECET Group, Pharmaceutical Sciences, Medical Research Institute, School of Medicine, University of Antioquia, Medellín, Colombia \\ 3 Department of Education, University of Antioquia, Medellín, Colombia \\ 4 PECET Group, University of Antioquia, Medellín, Colombia \\ 5 CES University, Medellín, Colombia \\ 6 Departments of Pathology and Laboratory Medicine \& Dermatology, University of Rochester Medical Center, School of Medicine and \\ Dentistry, Rochester, NY, USA
}

Key words: areae compositae of the heart, endemic pemphigus foliaceus, MYZAP, left cardiac hypertrophy, p0071, ARVCF, desmoplakins I and II

Citation: Abreu-Velez AM, Upegui-Zapata YA, Valencia-Yepes CA, Upegui-Quiceno E, Jiménez-Echavarría AM, Niño-Pulido CD, Smoller BR, Howard MS. Involvement of the areae compositae of the heart in endemic pemphigus foliaceus. Dermatol Pract Concept. 2019;9(3):181-186. DOI: https://doi.org/10.5826/dpc.0903a02

Accepted: March 14, 2019; Published: July 31, 2019

Copyright: (02019 Abreu-Velez et al. This is an open-access article distributed under the terms of the Creative Commons Attribution License, which permits unrestricted use, distribution, and reproduction in any medium, provided the original author and source are credited.

Funding: This work was funded by Georgia Dermatopathology Associates; Mineros SA, Medellín, Colombia; Hospital Nuestra Señora del Carmen, El Bagre, Colombia; The Embassy of Japan in Colombia; and the El Bagre Mayoral Office.

Competing interests: The authors have no conflicts of interest to disclose.

Authorship: All authors have contributed significantly to this publication.

Corresponding author: Ana Maria Abreu-Velez, MD, PhD, DrSc, Georgia Dermatopathology Associates, 1534 North Decatur Road, NE, Suite 206, Atlanta, GA 30307-1000, USA. Email: abreuvelez@yahoo.com

ABSTRACT Background: A new variant of endemic pemphigus foliaceus in El Bagre (El Bagre-EPF), Colombia, South America, shares features with Senear-Usher syndrome and occurs in an endemic fashion. Patients affected by El Bagre-EPF have heterogeneous antigenic reactivity not only to the skin but to other organs, including the heart. Here we test for autoantibodies to the areae compositae of the heart (structure consisting of typical desmosomal amalgamated fascia adherens molecules) and evaluate any possible clinical correlation.

Methods: A case-control study comparing 45 patients and 45 controls from the endemic area, matched by demographics including age, gender, weight, work activities, and comorbidities, was performed. Direct and indirect immunofluorescence, immunohistochemistry, confocal microscopic studies, and echocardiogram studies were completed.

Results: The main clinical abnormally seen in the El Bagre-EPF patients was left ventricular hypertrophy in $15 / 45$ patients, compared with no such findings in the control population $(P<0.1)$. Seventy 
ABSTRACT percent of El Bagre-EPF patients and none of the controls displayed polyclonal autoreactivity using different immunoglobulins and complement to the areae compositae of the heart using different methods and antibodies $(\mathrm{P}<0.1)$.

Conclusions: Patients affected by El Bagre-EPF demonstrated autoantibodies to the areae compositae of the heart. This finding was associated with left ventricular hypertrophic cardiomyopathy. The areae compositae may play a role in cell junction tension and the El Bagre-EPF patients' autoantibodies possibly disrupting these junctions and thereby contributing to the left ventricular hypertrophy.

\section{Introduction}

A new variant of endemic pemphigus foliaceus in El Bagre (El Bagre-EPF) (also known as pemphigus Abreu-Manu) occurs in a well-defined geographic area of Colombia, South America. This disease provides an outstanding natural model for studying the interactions among genetics, the immune system, and possible environmental risk factors in the development of autoimmunity [1-8]. Continuous exogenous antigenic stimulation and a genetic predisposition may be required in the pathogenesis of this disease [4-8]. Patients affected by El Bagre-EPF have autoantibodies to multiple cell junctions in the skin and one-third of them also demonstrate autoantibodies against other organs' cell junctions. We tested for autoreactivity to a more complex cell junction in the heart, the areae compositae, and evaluated for any possible clinical associations.

\section{Materials and Methods}

A case-control study on 45 patients affected by El BagreEPF and 45 controls from the endemic area matched by age, gender, and work activities was performed. A human quality assurance review board at the Nuestra Señora del Carmen Hospital in El Bagre approved the studies. The study participants signed consent forms, and no patient identifiers were retained. To make the diagnosis of El Bagre-EPF, we took skin biopsies from the chest and they were evaluated by hematoxylin and eosin histology, direct and indirect immunofluorescence (DIF, IIF), and immunoblotting [4-8]. Only patients meeting diagnostic criteria for El Bagre-EPF were included, specifically: (1) patients displayed clinical and epidemiological features described for this disease; (2) patients lived in the endemic area; and (3) patient serum displayed intercellular staining between epidermal keratinocytes and the basement membrane zone of the skin, via either DIF or IIF using fluorescein isothiocyanate (FITC)-conjugated monoclonal antibodies to human total immunoglobulin (Ig) G or IgG4, as described elsewhere [4-8]. Furthermore, (4) each patient's serum tested positive by immunoblotting for reactivity against desmoglein-1 (Dsg1), as well as for plakin molecules as previously described [4-8]; (5) each patient's serum immunoprecipitated a concanavalin A affinity-purified antigen bovine tryptic 45-48 kDa fragment of Dsg1 [7]; and (6) each patient's serum yielded a positive result using an enzyme-linked immunosorbent assay test when screening for autoantibodies to pemphigus foliaceus antigens [8].

In addition, blood pressure was taken in the patients and controls.

\section{Direct and Indirect Immunofluorescence}

In brief, for DIF from skin biopsies and IIF we incubated 4-micron-thickness sections on slides with secondary antibodies as previously described (4-10). Rat and cow were used for the IIF and were partially permeabilized using $1 \times$ phosphatebuffered saline with $0.1 \%$ Triton and blocked with $1 \%$ normal goat serum [4-10]. FITC-conjugated rabbit anti-total IgG, IgA, IgM, complement/C1q, and complement/C3 were used. These antibodies were used at 1:25 dilution. We also used fibrinogen and albumin at 1:50 dilution. All of the preceding antibodies were obtained from Dako (Carpinteria, CA, USA). In addition, anti-human $\operatorname{IgE}$ antiserum (Epsilon chain) was obtained from Kent Laboratories (Bellingham, WA, USA) and anti-human IgD antibodies from Southern Biotechnology (Birmingham, AL, USA). These latter antibodies were used at 1:25 dilution. The DIF slides were counterstained with 4',6-diamidino-2-phenylindole (DAPI) (Pierce, Rockford, IL, USA). Commercial antibodies to known components of the areae compositae of the heart were used to study possible colocalization markers with the patients' autoantibodies. These include mouse monoclonal multiepitope cocktail to anti-desmoplakin I and II (DSPI-II) (catalog no. 65146), to armadillo repeat gene deleted in velocardiofacial syndrome (ARVCF) polyclonal antibody (catalog no. GP155) (secondarily used Alexa Fluor 555 goat-antiguinea pig IgG [H\&L], Molecular Probes Life Technologies incorporated by ThermoFisher Scientific, Waltham, MA, USA) [9]. We also used mouse monoclonal multiepitope cocktail to anti-p0071 (catalog no. 651166), mouse monoclonal antibody to Myozap (also known as MIZAP) (catalog no. 651169) as the secondary antibodies to the DSPI-II, to p007, and to Myozap goat anti-mouse Texas red-conjugated IgG (H\&L) (ThermoFisher). The antibodies to Myozap, DSPI-II, p0071, and ARCVF were all from Progen Biotechnik (Heidelberg, Germany). The samples were consistently run with positive and negative controls. We classified our findings as negative 

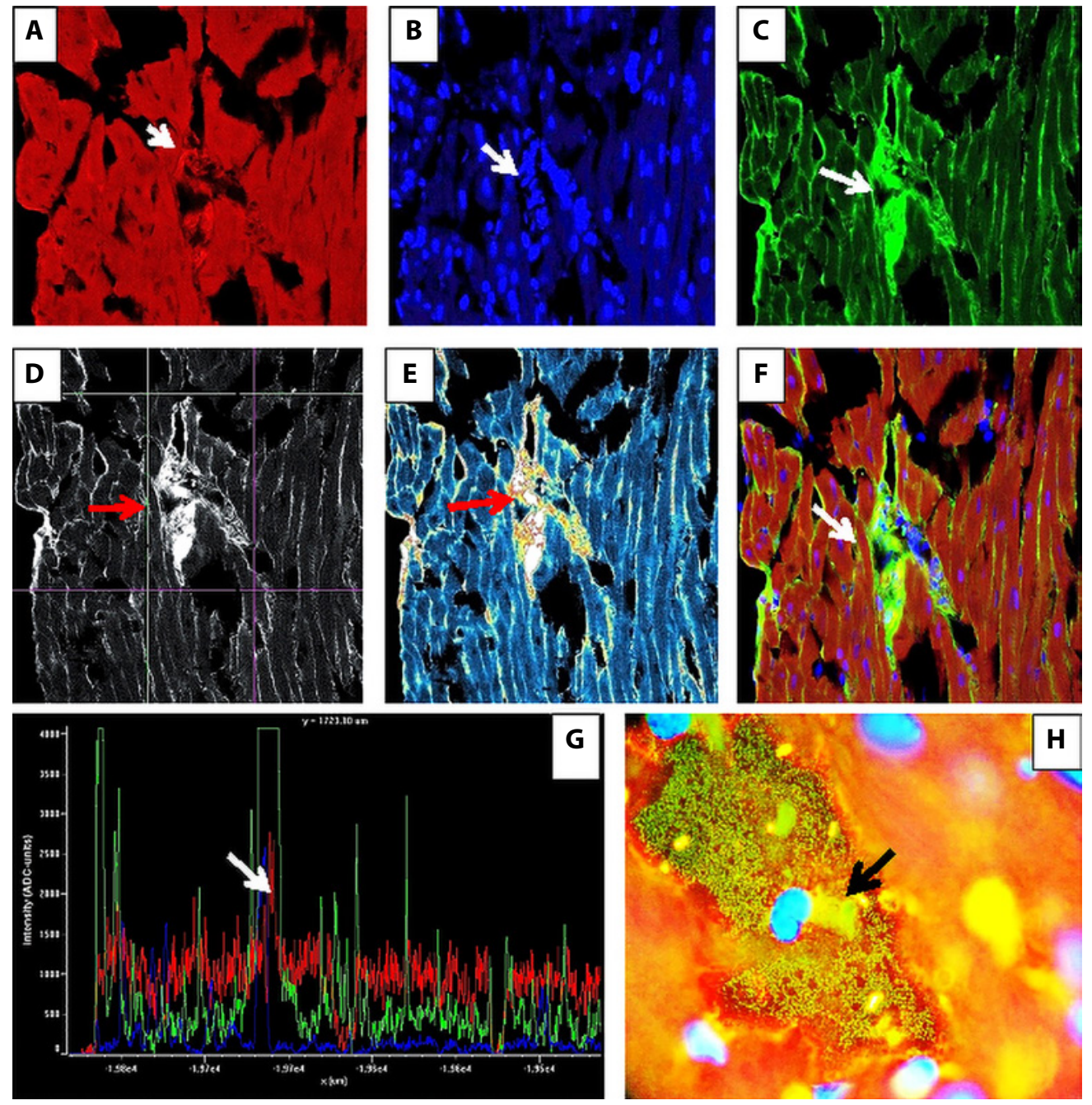

Figure 1. (A) Confocal microscopy showing colocalization of the El Bagre-EPF patients with the commercial antibody to MIZAP (white arrow, red stain). (B) The area composita has nuclei as shown in the positive stain with DAPI (white arrow, blue stain). (C) El Bagre-EPF autoantibodies stained using anti-human IgG-FITC-conjugated antibodies against the area composita of the heart (white arrow, green stain). (D, E) Using pseudo color, the shape of the area composita is positive (red arrows). (A-F) $\times 630$. (G) The overlapping of the peaks of the fluorochromes to El Bagre-EPF in FITC and MIZAP with Texas red at the area composita of the heart (white arrows). (H) An overlapping of DAPI, El Bagre-EPF autoantibodies, and MIZAP $(\times 1,000)$ (white arrow). [Copyright: (02019 Abreu-Velez et al.]

$(-)$, weakly positive $(+)$, moderate positive $(++)$, positive $(+++)$ and strongly positive $(++++)$.

\section{B-Mode 2-Dimensional Ultrasound Imaging}

We tested for any cardiovascular pathology. VisualSonics ultrasound (Fujifilm, Toronto, Ontario, Canada) was used, and the testing was performed as described [11]. M-mode echocardiograms were done and recorded at $50 \mathrm{~mm} / \mathrm{second}$ paper speed using black and white photographic paper. The following M-mode parameters were analyzed: left ventricular fractional shortening (LVFS), left ventricular end-diastolic diameter (LVEDD), left ventricular end-systolic diameter (LVESD), posterior wall thickness (PWTh), left ventricular end-diastolic radius/posterior wall thickness (R/Th), interventricular septum thickness (IVSTh), percentage of IVS systolic thickening (IVS\%Th), percentage of PW systolic thickening (PW\% Th), and left atrium dimensions (LA).

\section{Statistical Analysis}

We used Fisher exact test to compare 2 nominal variables (eg, positive and negative) of antibody response. We also compared the differences between patient cases and controls when evaluating positivity of the El Bagre-EPF autoantibodies. $\mathrm{P}<0.1$ with a $98 \%$ confidence interval (or better) was considered statistically significant. For all statistical analyses, the software GraphPad QuickCalcs (GraphPad Software Inc., La Jolla, CA, USA) was used.

\section{Results}

Seventy percent of El Bagre-EPF cases and none of the controls displayed polyclonal autoreactivity with different immunoglobulins and complement components to the areae compositae of the heart using different methods and antibodies $(\mathrm{P}<0.1)$. The IIF showed colocalization with the commercial antibodies to MIZAP, ARVCF, DSPI-II, and p0071 in the tested species (rat and cow). The positive antibodies were anti-human IgG, IgM, C3C, C1Q, fibrinogen, and albumin (Figures 1 and 2).

In Table 1, we present the data of the presence of autoantibodies against the areae compositae of the heart using IIF comparing serum El Bagre-EPF autoantibodies in cases vs controls. The patients' daily dosage of prednisone is also presented in this table. 

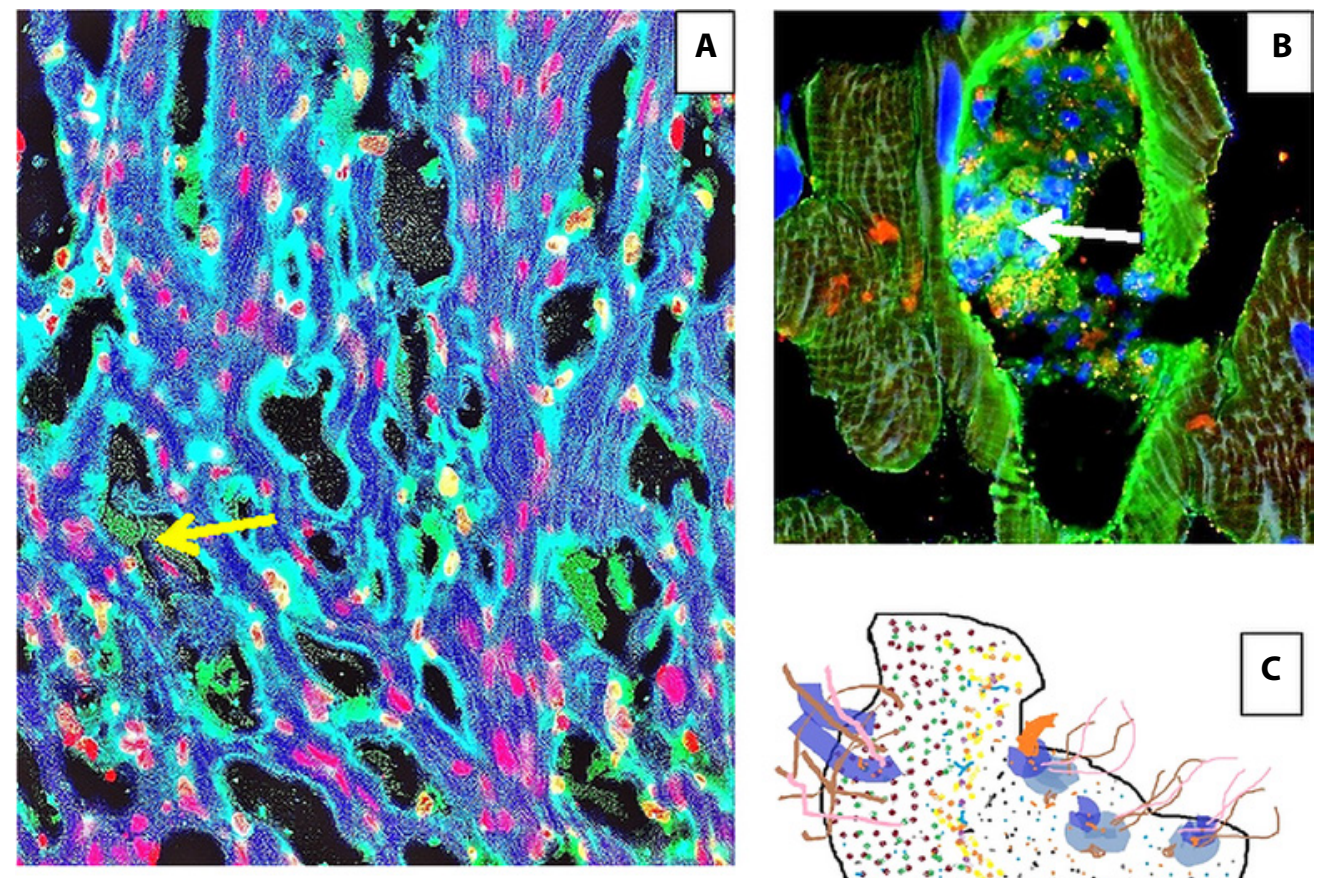

Figure 2. (A) Confocal microscopic image shows positive staining with El BagreEPF autoantibodies labeled with FITC-conjugated antihuman $\operatorname{IgG}$ (green staining) colocalizing with the antibody to ARVCF (Texas redconjugated) at multiple areae compositae of the heart (yellow arrow) $(\times 1,000)$. (B) A zoom of the areae compositae of the heart (white arrow shows the complexity

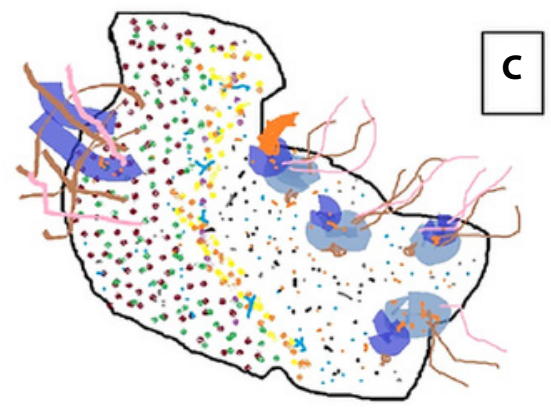
of the multiple dotted molecules inside it) $(\times 140)$. (C) Diagram of the areae compositae. [Copyright: @2019 Abreu-Velez et al.]

Table 1. Presence of autoantibodies (Ab) against the areae compositae of the heart using IIF and cow as antigen source and comparison with the respective titers of seric autoantibodies in cases vs controls and their daily dosage of prednisone

\begin{tabular}{|l|c|c|c|c|c|c|}
\hline $\begin{array}{c}\text { Autoantibodies } \\
\text { and Markers }\end{array}$ & El Bagre-EPF & $\begin{array}{c}\text { Titers of Ab in } \\
\text { Serum }\end{array}$ & $\begin{array}{c}\text { Daily Dosage of } \\
\text { Oral Prednisone }\end{array}$ & Controls & Titers of Ab & P Values \\
\hline IgG & $15 / 45$ & $(320)$ & $10 \mathrm{mg}$ & $0 / 45$ & $(0)$ & $<0.01$ \\
\hline Fibrinogen & $15 / 45$ & $(320)$ & $15 \mathrm{mg}$ & $0 / 45$ & $(0)$ & $<0.01$ \\
\hline IgM & $13 / 45$ & $(160)$ & $20 \mathrm{mg}$ & $0 / 45$ & $(20)$ & $<0.01$ \\
\hline Albumin & $11 / 45$ & $(160)$ & $25 \mathrm{mg}$ & $0 / 45$ & $(20)$ & $<0.01$ \\
\hline C3c & $13 / 45$ & $(160)$ & $30 \mathrm{mg}$ & $0 / 45$ & $(20)$ & $<0.01$ \\
\hline C1q & $12 / 45$ & $(80)$ & $30 \mathrm{mg}$ & $0 / 45$ & $(20)$ & $<0.01$ \\
\hline IgA & $15 / 45$ & $(40)$ & $30 \mathrm{mg}$ & $0 / 45$ & $(0)$ & $<0.01$ \\
\hline IgD & $15 / 45$ & $(40)$ & $15 \mathrm{mg}$ & $0 / 45$ & $(0)$ & $<0.01$ \\
\hline IgE & $7 / 45$ & $(40)$ & $20 \mathrm{mg}$ & $0 / 45$ & $(0)$ & $<0.01$ \\
\hline Kappa & $15 / 45$ & $(160)$ & $15 \mathrm{mg}$ & $0 / 45$ & $(0)$ & $<0.01$ \\
\hline Lambda & $15 / 45$ & $(160)$ & $15 \mathrm{mg}$ & $0 / 45$ & $(0)$ & $<0.01$ \\
\hline
\end{tabular}

The main echocardiogram abnormalities seen in the El Bagre-EPF patients include a left ventricular hypertrophy (LVH) in 15/45 patients, and this was not identified in any of the control patients $(\mathrm{P}<0.1)$. The echocardiogram findings revealed the following parameters in all 15 patients: LVH and normalization of left ventricular dimensions and function were done. The average measurement of the 15 patients was $11 \mathrm{~cm}$; LVFS changed from $15.0 \pm 5.2 \%$ to $39.7 \pm 5.4 \%$ (P $<0.1)$, LVEDD from $6.6 \pm 0.6$ to $4.6 \mathrm{~cm}(\mathrm{P}<0.01)$, LVESD from $5.6 \pm 0.8$ to $2.8 \pm 0.6 \mathrm{~cm}(\mathrm{P}<0.01)$, PWTh from $1.1 \pm$
0.1 to $1.2 \pm 0.1 \mathrm{~cm}$ (not significant), R/Th from $3.1 \pm 0.5$ to $2.0 \pm 0.4 \mathrm{~cm}(\mathrm{P}<0.01)$, IVSTh from $1.2 \pm 0.3$ to $1.5 \pm 0.3 \mathrm{~cm}$ $(\mathrm{P}<0.01)$, IVS\%Th from $14.2 \pm 4.1 \%$ to $28.5 \pm 7.8 \%(\mathrm{P}<$ $0.01)$, PW\% Th from $31.0 \pm 14.4$ to $54.3 \pm 19.6 \%(\mathrm{P}<0.01)$, and LA from $4.6 \pm 0.6$ to $3.5 \pm 0.9 \mathrm{~cm}(\mathrm{P}<0.01)$.

Blood pressure levels were similar in the cases and controls.

Using IIF, 23/45 patients affected by El Bagre-EPF had anti-human IgG-FITC-conjugated autoantibodies and com- 
plement directed to the areae compositae of the heart $(\mathrm{P}<0.1)$ (Figures 1 and 2). No controls were positive.

\section{Discussion}

The areae compositae of the heart is composed of an amalgamation of mixed-type cell-cell adhering junctions with desmosomes, adhering junctions, and some vessel junctions [9,12-19]. In recent years it has become clear that numerous other junction types exist that are different from the classically recognized junctions such gap, desmosome, hemidesmosome, tight junctions, and adherens junctions, and some of them are located where 3 or more cell junctions converge [20]. The biological constitution of the area composita and its clinical importance has recently gained attention. Only a few studies on the areae compositae have shown that mutations in the areae compositae protein $\alpha \mathrm{T}$-catenin are associated with arrhythmogenic right ventricular cardiomyopathy [20,21]. Our study provides new information about the possible role of the areae compositae, especially at the left ventricle, where stronger junctions are needed to handle the higher intraventricular pressure. Further investigations are needed [22].

Hypertrophic cardiomyopathy is clinically defined by the presence of increased left ventricular wall thickness that is not solely explained by abnormal loading condition [23]. The most common cause of LVH is high blood pressure (hypertension). The patients in this study who demonstrated LVH had no evidence of high blood pressure [24]. Other causes of LVH include athletic hypertrophy (a condition related to exercise). The patients in this study, although they work outside as farmers and or miners, are not athletes. Valve disease is also a cause of LVH (some of the patients have valve disease due to the presence of autoantibodies) (manuscript in preparation). This presents an alternative explanation for the increased incidence of LVH in our patient population. Other conditions such hypertrophic cardiomyopathy, and congenital heart disease, such as autosomal dominant trait caused by cardiac sarcomere protein gene mutation, can also give rise to LVH. (So far these 2 conditions have been undetected in any of our patients, although we suspect they carry several genetic anomalies.) Other conditions, such as myocardial infarction and dilated cardiomyopathy, can cause cardiomegaly.

Experimentally mutated MIZAP in mice results in LVH [25]. El Bagre-EPF autoantibodies colocalize with MIZAP and other molecules at the areae compositae of the heart. The areae compositae is part of the contractile tissue of the heart making specific cell-cell contacts necessary to ensure strong mechanical and electrochemical coupling during beating. These contact sites, termed the intercalated discs, have gained increased attention recently because of their potential involvement in cardiac disease.

\section{Conclusions}

We conclude that El Bagre-EPF patients have autoantibodies to the areae compositae of the heart colocalizing with MIZAP, ARVCF, DSPI-II, and p0071. Clinically, these patients often present with LVH. As shown in this study, the localization and nature of the autoantibodies in autoimmune diseases may help us to understand the biological and physiological importance of the pathophysiology in this category of diseases.

\section{References}

1. Abreu-Velez AM, Messias-Reason IJ, Howard MS, et al. Endemic pemphigus foliaceus over a century: part 1. North Am J Med Sci. 2010:2(2):51-59.

2. Abreu-Velez AM, Roselino AM, Howard MS, et al. Endemic pemphigus foliaceus over a century: part 2. North Am J Med Sci. 2010;2(3):114-125.

3. Abreu-Velez AM, Calle-Isaza J, Howard MS. Autoimmune epidermal blistering diseases. Our Dermatol Online. 2013;4(Suppl 3):631-646.

4. Abreu-Velez A, Hashimoto T, Bollag W, et al. A unique form of endemic pemphigus in Northern Colombia. J Am Acad Dermatol. 2003;49(4):599-608.

5. Abreu-Velez AM, Beutner E, Montoya F, et al. Analyses of autoantigens in a new form of endemic pemphigus foliaceus in Colombia. J Am Acad Dermatol. 2003;49(4):609-614.

6. Hisamatsu Y, Abreu-Velez AM, Amagai M, et al. Comparative study of autoantigen profile between Colombian and Brazilian types of endemic pemphigus foliaceus by various biochemical and molecular biological techniques. J Dermatol Sci. 2003;32(1):3341.

7. Abréu-Vélez AM, Javier Patiño P, Montoya F, et al. The tryptic cleavage product of the mature form of the bovine desmoglein 1 ectodomain is one of the antigen moieties immunoprecipitated by all sera from symptomatic patients affected by a new variant of endemic pemphigus. Eur J Dermatol. 2003;13(4):359-366.

8. Abréu-Vélez AM, Yepes MM, Patiño PJ, et al. F. A cost-effective, sensitive and specific enzyme linked immunosorbent assay useful for detecting a heterogeneous antibody population in sera from people suffering a new variant of endemic pemphigus. Arch Dermatol Res. 2004;295(10):434-441.

9. Abreu-Velez AM, Zhe J, Howard MS, Jiao Z. Heart immunoreactivity in patients affected by a new variant of endemic pemphigus foliaceus in El-Bagre, Colombia, South America.J Clin Immunol. 2011;31(6):985-997.

10. Abreu-Velez AM, Howard MS, Grossniklaus HE, et al. Neural system antigens are recognized by autoantibodies from patients affected by a new variant of endemic pemphigus foliaceus in Colombia. J Clin Immunol. 2011;31(3):356-368.

11. Takahashi H, Hasegawa H, Kanai H. Temporal averaging of twodimensional correlation functions for velocity vector imaging of cardiac blood flow. J Med Ultrason. 2015;42(3):323-330.

12. Goossens S, Janssens B, Bonné $S$, et al. A unique and specific interaction between alphaT-catenin and plakophilin-2 in the area composita, the mixed-type junctional structure of cardiac intercalated discs. J Cell Sci. 2007;120(Pt 12):2126-2136.

13. Franke WW, Borrmann CM, Grund C, et al. The area composita of adhering junctions connecting heart muscle cells of vertebrates, 
I: molecular definition in intercalated disks of cardiomyocytes by immunoelectron microscopy of desmosomal proteins. Eur J Cell Biol. 2006;85(2):69-82.

14. Borrmann CM, Grund, C, Kuhn C, et al. The area composita of adhering junctions connecting heart muscle cells of vertebrates, II: colocalizations of desmosomal and fascia adhaerens molecules in the intercalated disk. Eur J Cell Biol. 2006;85(6):469-485.

15. Franke WW, Schumacher H, Borrmann CM, et al. The area composita of adhering junctions connecting heart muscle cells of vertebrates, III: assembly and disintegration of intercalated disks in rat cardiomyocytes growing in culture. Eur J Cell Biol. 2007;86(3):127-142.

16. Pieperhoff S, Franke WW. The area composita of adhering junctions connecting heart muscle cells of vertebrates, IV: coalescence and amalgamation of desmosomal and adhaerens junction components-late processes in mammalian heart development. Eur J Cell Biol. 2007;86(7):377-391.

17. Pieperhoff S, Schumacher H, Franke WW. The area composita of adhering junctions connecting heart muscle cells of vertebrates, $\mathrm{V}$ : the importance of plakophilin-2 demonstrated by small interference RNA-mediated knockdown in cultured rat cardiomyocytes. Eur J Cell Biol. 2008;87(7):399-411.

18. Pieperhoff $S$, Franke WW. The area composita of adhering junctions connecting heart muscle cells of vertebrates, VI: different precursor structures in non-mammalian species. Eur J Cell Biol. 2007;87(7):413-430.

19. Pieperhoff S, Borrmann C, Grund C, et al. The area composita of adhering junctions connecting heart muscle cells of vertebrates,
VII: the different types of lateral junctions between the special cardiomyocytes of the conduction system of ovine and bovine hearts. Eur J Cell Biol. 2010;89(5):365-378.

19. Higashi T, Miller AL. Tricellular junctions: how to build junctions at the TRICkiest points of epithelial cells. Mol Biol Cell. 2017;28(15):2023-2034.

20. van Hengel J, Calore M, Bauce B, et al. Mutations in the area composita protein $\alpha \mathrm{T}$-catenin are associated with arrhythmogenic right ventricular cardiomyopathy. Eur Heart J. 2013;34(3):201210.

21. Li J, Goossens S, van Hengel J, et al. Loss of aT-catenin alters the hybrid adhering junctions in the heart and leads to dilated cardiomyopathy and ventricular arrhythmia following acute ischemia. $J$ Cell Sci. 2012;125(Pt 4):1058-1067.

22. Perriard JC, Hirschy A, Ehler E. Dilated cardiomyopathy: a disease of the intercalated disc? Trends Cardiovasc Med. 2003;13(1):3038.

23. Stewart MH, Lavie CJ, Shah S, et al. Prognostic implications of left ventricular hypertrophy. Prog Cardiovasc Dis. 2018;61(56):446-455

24. Loncaric F, Bijnens B, Sitges M. Added value of cardiac deformation imaging in differential diagnosis of left ventricular hypertrophy. Glob Cardiol Sci Pract. 2018;2018(3):21.

25. Rangrez AY, Eden M, Poyanmehr R, et al. Myozap deficiency promotes adverse cardiac remodeling via differential regulation of mitogen-activated protein kinase/serum-response factor and $\beta$-catenin/gsk- $3 \beta$ protein signaling. J Biol Chem. 2016;291(8):4128-4143. 